\title{
DOING OU UNDOING BUSINESS?
}

\author{
Bianca Castellar de Faria ${ }^{1}$ \\ Naurican Ludovico Lacerda ${ }^{2}$
}

\section{Resumo}

O presente artigo traz uma reflexão sobre a metodologia do relatório do Banco Mundial que compara o ambiente de negócios em 190 diferentes países. Esse relatório traz o ranking de doze áreas relacionadas a desenvolvimento de diversas áreas da economia, sendo uma delas o "registro de propriedade". A metodologia utilizada pelo relatório apresenta fragilidades, colocando em xeque a credibilidade do projeto global. Na comparação do relatório e do ranking do registro de propriedade entre Brasil e Estados Unidos, foram localizadas inconsistências relacionadas à metodologia, como critério aberto, subjetividade de interpretação, omissão de procedimentos obrigatórios e inclusão de procedimentos inexistentes.

Palavras-chave: Relatório Doing Business, Banco Mundial, Registro de imóveis, propriedade, metodologia.

\section{DOING OR UNDOING BUSINESS?}

\begin{abstract}
This article discusses the methodology used by the World Bank's report that analyses the business environment in 190 different countries. This report brings the ranking of twelve areas related to the development of various areas of the economy, one of which is the "property registry". The methodology used by the report presents weaknesses, calling in to check the credibility of the global project. In the comparison of the report between Brazil and the United States, inconsistencies related to the methodology were found, such as open criteria, the subjectivity of interpretation, omission of mandatory procedures, and inclusion of non-existent procedures.
\end{abstract}

Keywords: Doing Business Report, World Bank, Property Registry, property, methodology.

\section{INTRODUÇÃO}

Um ano antes do término da Segunda Guerra Mundial, quarenta e quatro países se reuniram para a Conferência das Nações Unidas, com o objetivo de criar estratégias para

\footnotetext{
${ }^{1}$ Doutoranda em Direito pela UNIVALI e pela Delaware University. Mestre em Direito Público pela UFRGS. Titular do $1^{\text {o }}$ Registro de Imóveis de Joinville-SC, Rua Orestes Guimarães, 538, Joinville-SC. Email: bianca@1rijoinville.com.br.

${ }^{2}$ Doutorando em Direito pela UNIVALI e pela Delaware University. Mestre em Direito Constitucional pelo IDP-DF. Titular do $1^{\circ}$ Tabelionato de Protesto, Registro de Títulos e Documentos e Pessoas Jurídicas de Goiânia-GO, Rua 9, 1.111. Setor Oeste, Goiânia-GO. Email: naurican@ gmail.com.
} 
reconstrução econômica dos países devastados pela Guerra e para o fortalecimento econômico dos países em desenvolvimento (WORLD BANK, 2021).

Embora a conferência tenha resultado na formação de duas instituições: o Fundo Monetário Internacional (FMI) e o Banco Internacional para a Reconstrução e o Desenvolvimento (Banco Mundial), a criação do Banco Mundial não foi o foco principal. Durante o final da década de 1990, o Banco Mundial voltou para as áreas de prevenção de conflitos, reconstrução pós-conflito e assistência para os países redirecionarem suas economias após grandes mudanças políticas.

A partir de 2002, o Banco Mundial, por meio do projeto Doing Business (WORLD BANK, 2021), passou a medir, analisar e comparar as regulamentações existentes em 190 diferentes países. Este relatório serve como ferramenta para se medir o impacto das regulamentações sobre as atividades empresariais ao redor do mundo, classificando os países em diferentes aspectos. Assim, o objetivo do Doing Business é incentivar os países a competir para alcançar uma regulamentação mais eficiente; oferecer padrões de referência sobre reformas regulatórias; e servir como uma ferramenta para a análise do ambiente de negócios de cada país.

Analisando o relatório do "registro de propriedade" do Brasil e dos Estados Unidos, tanto pelo método indutivo quanto comparativo, foram localizadas várias inconsistências e fragilidades que retiram a credibilidade do relatório global, na medida em que passa a ser alvo de críticas pela sua metodologia.

O objetivo, portanto, do presente artigo é apontar as inconsistências metodológicas encontradas, a fim de que o relatório não prejudique os países com classificações errôneas (fazendo um undoing business) e atinja sim seu objetivo, que é de auxiliar no desenvolvimento da economia mundial (doing business). 


\section{O RELATÓRIO DOING BUSINESS E SEUS CRITÉRIOS}

O relatório abrange doze áreas distintas de regulamentação de negócios. Dez dessas áreas formam uma classificação mundial, trazendo a pontuação de cada um dos 190 países. O projeto também analisa a contratação de trabalhadores e a contratação com o governo, sem incluir na pontuação e na classificação da facilidade de se fazer negócios. Esses são os tópicos que formam o ranking mundial: 1 - Iniciando um negócio, 2 - Lidando com Licenças de Construção, 3 - Obtendo eletricidade, 4 - Registro de Propriedade, 5 - Obtenção de crédito, 6 - Proteção a investidores minoritários, 7 - Pagamento de tributos, 8 - Importação e Exportação, 9 - Execução de contratos e 10 - Resolução de insolvência.

Uma das áreas pesquisadas pelo Banco Mundial é o "registro de propriedades", que analisa quantidade de procedimentos necessários para se registrar a transferência de um bem imóvel, além do prazo, da qualidade e do custo.

A fim de compreender quais requisitos foram levados em consideração para a pontuação e para a classificação, essencial compreender previamente a metodologia utilizada pelo Banco Mundial.

\subsection{Metodologia utilizada para a avaliação do "registro de propriedade"}

O relatório Doing Business, a fim de analisar, pontuar e classificar o registro de propriedades em cada um dos cento e noventa países, considera a sequência completa de procedimentos necessários para a aquisição de uma propriedade. Em relação aos procedimentos relacionados, o estudo mede o prazo e o custo de cada um deles. Juntamente com a análise de custo e prazo, o Doing Business também mede a qualidade do sistema de administração de terras em cada economia. Nessa análise de qualidade, o Banco Mundial considera cinco quesitos: confiabilidade da infraestrutura, transparência das informações, cobertura geográfica, resolução de disputas fundiárias e igualdade de acesso aos direitos de propriedade (WORLD BANK, 2021). 
Conforme convencionado pela metodologia do projeto do Banco Mundial, a contagem do prazo se inicia com a obtenção dos documentos necessários à transferência de propriedade e se encerra a partir do momento que o registro puder ser oponível a terceiros e quando o adquirente puder utilizar o imóvel para a expandir seus negócios, como garantia de um empréstimo bancário ou puder revendê-lo. Todos os procedimentos exigidos por lei ou necessários na prática estão incluídos, sejam de responsabilidade do vendedor ou do comprador, sendo todas as informações são prestadas por advogados, tabeliães e registradores de imóveis.

Para que os dados sejam passíveis de comparação entre os cento e noventa diferentes países, várias suposições são feitas em relação às partes interessadas, ao imóvel e aos procedimentos. Quanto às partes, comprador e vendedor devem ser sociedades de responsabilidade limitada (ou seu equivalente legal), localizadas na maior cidade comercial do país. Para onze economias, os dados também são coletados para a segunda maior cidade de negócios, que é o caso do Brasil e dos Estados Unidos. No Brasil, são colhidos dados de São Paulo e do Rio de Janeiro e, nos Estados Unidos, de Nova Iorque e de Los Angeles.

O imóvel objeto da transação imobiliária deve ter um valor de venda de 50 vezes a renda per capita do respectivo país, ser integralmente do vendedor, sem qualquer registro de garantia imobiliária, livre de ação judicial, localizado na cidade investigada e composto por um terreno e um prédio. A área aproximada do terreno é de 557,4 metros quadrados (6.000 pés quadrados). Considerando a renda per capita de cada um dos países e a cotação do dólar de R\$ 5,20 (BANCO CENTRAL DO BRASIL: 30/08/2021), analisou-se uma aquisição de um imóvel de R \$ 1.770.000,00 no Brasil e de US\$ 3.169.355,00 nos Estados Unidos.

\subsection{Ranking 2020: Estados Unidos e Brasil}

No ranking mundial apresentado pelo relatório Doing Business 2020, os Estados Unidos ocupam o $6^{\circ}$ lugar em termos de facilidade para a realização de negócios, sendo que na área relacionada a "Registro de Propriedade", ocupam a 39a posição. 
Figura 1 - Ranking geral dos EUA no Doing Business

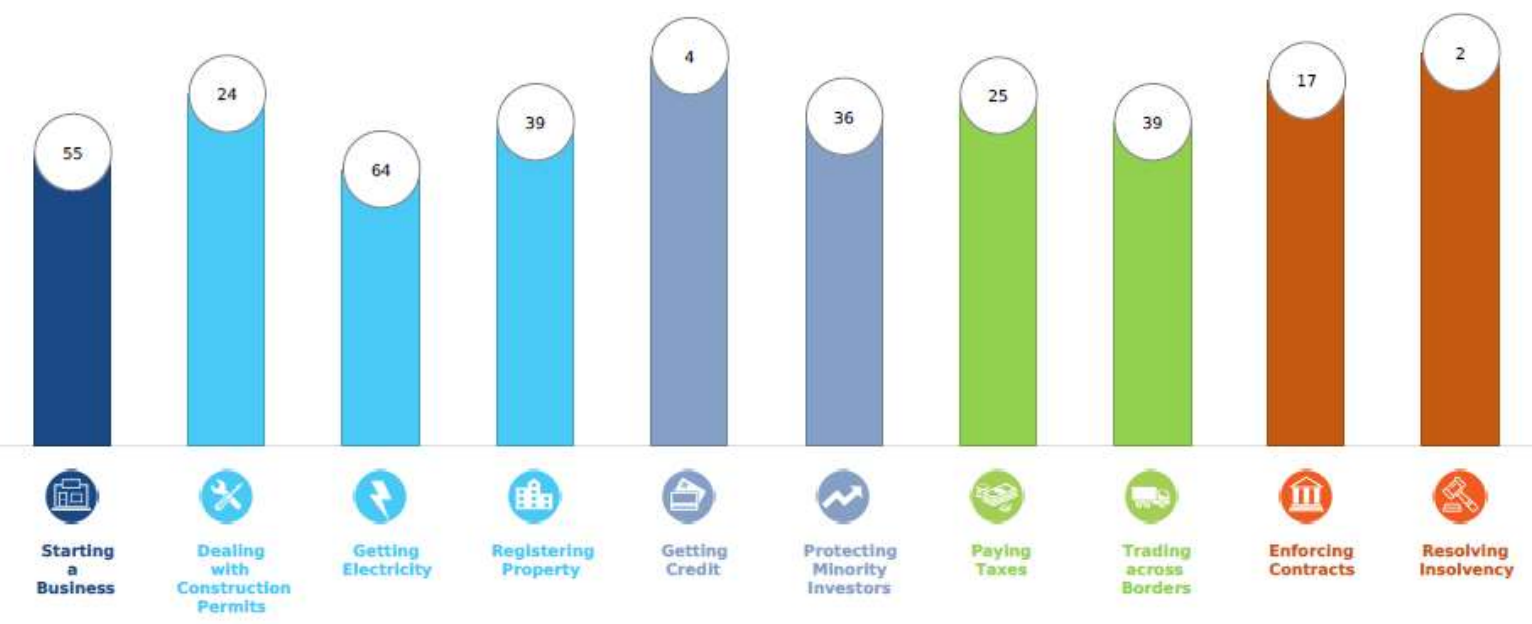

Fonte: https://www.doingbusiness.org/en

Já o Brasil, no ranking mundial ocupa a $124^{a}$ posição ${ }^{3}$ em termos de facilidade para a realização de negócios, sendo que na área relacionada à "Registro de Propriedade" ocupa o $133^{\circ}$ lugar.

Figura 2 - Ranking geral do Brasil no Doing Business

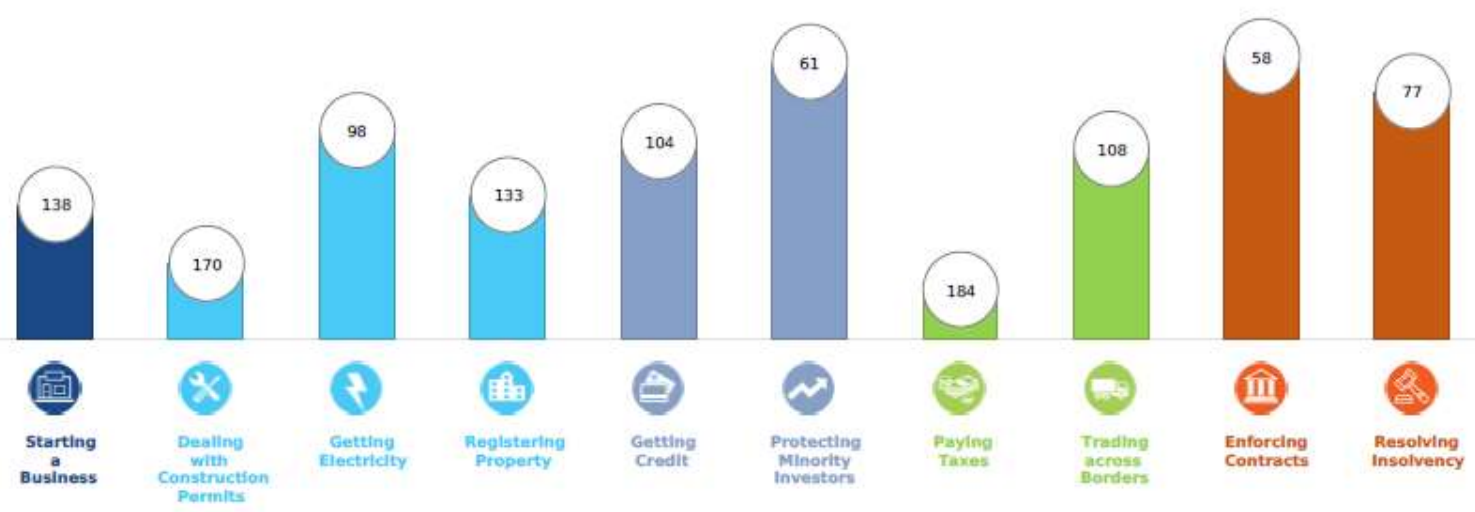

Fonte: https://www.doingbusiness.org/en

No que diz respeito ao "registro da propriedade", os Estados Unidos receberam a 39a colocação mundial, enquanto o Brasil a $133^{\mathrm{a}}$ posição. Na medida em que o relatório analisa

\footnotetext{
${ }^{3}$ WORLD BANK. Open Knowledge Repository. Disponível em: <https://openknowledge.worldbank.org>. Acesso em: 06 set. 2021.
} 
qualidade, complexidade, prazo e custo, tal ranking coloca o sistema registral imobiliário numa posição bem aquém da norte-americana, o que não se confirma quando analisamos os dois modelos.

\section{AS FRAGILIDADES DO RELATÓRIO DOING BUSINESS 2020}

O estudo de 190 economias é sem dúvida, uma louvável iniciativa do Banco Mundial e, certamente, serve para impulsionar uma série de reformas legislativas que objetivam melhorar o ambiente de negócios em cada um dos países envolvidos.

No entanto, no pequeno recorte que essa pesquisa se propôs a fazer, qual seja, a comparação da classificação do "registro de propriedade" no Brasil e nos Estados Unidos, as fragilidades encontradas foram muitas, o que retira a credibilidade de um relatório de abrangência e de importância global.

As falhas encontradas serão apontadas, de forma sistemática, e enviadas ao Banco Mundial, com o objetivo de servir como sugestões para o aperfeiçoamento do relatório Doing Business.

\subsection{Metodologia com "porta aberta"}

A metodologia do Doing Business define que todos os procedimentos exigidos por lei ou necessários na prática para a transferência da propriedade serão computados. Assim, não apenas os procedimentos previstos em lei são considerados, mas também os de costume da localidade. Na medida em que abre demasiadamente a diferentes interpretações e à subjetividade dos participantes, caracteriza-se como uma pesquisa interpretativa e não realista (LEE, 2008, p. 70). Essa é a primeira fragilidade do relatório.

Imaginem analisar diferentes procedimentos registrais imobiliários em 190 países sem ter um recorte bem definido? A margem para subjetividade é muito grande, afetando os resultados da pesquisa. 
Em razão disso, pelo fato de a metodologia deixar a "porta aberta" para os procedimentos registrais de costume e não apenas os previstos em lei, criou-se uma insegurança em relação aos dados apresentados. Exemplo disso, foi o relatório apontar quatorze diferentes procedimentos registrais imobiliários no Brasil e quatro nos Estados Unidos.

\subsection{Dois pesos e duas medidas}

Para que uma pesquisa tenha credibilidade e sirva para fortalecer a economia mundial, os parâmetros utilizados devem conter a maior simetria possível. Um dos elementos mais assimétricos da comparação entre o relatório do Brasil e o dos Estados Unidos foi o relacionado ao prazo, grande pêndulo do ranking mundial.

Tanto para a redação do contrato (deed) quanto para o registro do título perante o Registro de Imóveis norte-americano, foi computado, para cada um dos procedimentos, somente 1 dia. E a justificativa para que fosse de um dia é no sentido de que os efeitos do registro retroagem à data do protocolo.

Ora, no Brasil, existe regra expressa de retroação dos efeitos do registro à data do protocolo. O art. 1.246 do Código Civil preceitua que "o registro é eficaz desde o momento em que se apresentar o título ao oficial do registro, e este o prenotar no protocolo."

Assim, ou se considera 1 dia para ambos os sistemas registrais, levando em consideração a regra da retroação (que no Brasil é expressa e nos Estados Unidos não) ou se calcula exatamente a média de prazo de registro. O que não se pode fazer, nessa análise comparativa, é se utilizar da sistemática de "dois pesos e duas medidas".

\subsection{Omissão de procedimentos}

Em análise ao relatório Doing Business - United States 2020, é perceptível a ausência da menção de alguns procedimentos existentes numa operação imobiliária do sistema norteamericano. Três deles são a contratação do title insurance, a contratação de advogado e o 
recolhimento de dois impostos sobre a transferência do imóvel (transfer tax): de competência municipal e, também, estadual.

E essa omissão de procedimentos cria efeitos duplamente negativos à classificação do país estudado, haja vista uma das notas ser relacionada à quantidade de procedimentos e outra ao seu respectivo custo.

Pelo fato de a metodologia do Doing Business estabelecer que o imóvel objeto da transação imobiliária deve ter um valor de venda de 50 vezes a renda per capita do respectivo país, considerou-se a aquisição de um imóvel de US\$ 3.169.355 nos Estados Unidos.

Mesmo o relatório tendo mencionado apenas no item 1 o procedimento de obtenção de um relatório do título (title report), percebe-se que o custo englobou tanto o title search quanto o title insurance. E essa é uma constatação importante, na medida em que o relatório recebe muitas críticas pelo fato de não incluir um custo relevante da transação, qual seja, o seguro do título. Em simulação ${ }^{4}$ realizada com base no valor da transação estipulado na metodologia da pesquisa do Banco Mundial, foram encontrados valores bem semelhantes, quais sejam: US\$ 200 pelo title search e US\$ 13.045 para o title insurance.

Verifica-se, portanto, que o custo da transação title insurance foi levado em consideração, mas o procedimento em si (que também pontua negativamente) foi omitido.

Além disso, verifica-se no item 3 o procedimento relacionado ao preenchimento de formulários necessários para a transferência, quando os valores respectivos apontam, além do montante do questionário, os impostos pela transferência da propriedade (transfer tax), recolhidos tanto ao município quanto ao estado. Da mesma forma como ocorreu com o title insurance, os valores foram contabilizados, mas os procedimentos não.

Um procedimento que foi completamente omitido pelo relatório do Banco Mundial foi a contratação de advogado para realização de operação imobiliária, providência em Nova Iorque. Para esse procedimento, o custo ${ }^{5}$ de transação para avaliação da operação e para a

\footnotetext{
${ }^{4}$ Simulação de custo da transação realizado com base no valor de transação de US\$ 3.169.355. Disponível em: http://www.anytimeestimate.com/TITLE INSURANCE/ny-title-insurance.htm. Acesso em: 15/09/2021.

${ }^{5}$ Disponível em: https://www.prevu.com/blog/real-estate-attorney-fees-what-nyc-buyers-can-expect. Acesso em: 15 set. 2021.
} 
redação do deed seria aproximadamente de U\$ 2.000 a US\$ 6.000, dependendo do valor e da complexidade da negociação.

Considerando que não se trata de uma operação complexa, na medida em que a metodologia estabelece que o imóvel não tem gravame, mas com valor alto (US\$ 3.169.355), o custo da contratação do advogado oscilaria entre US\$ 3.000 e US\$ 5.000. O relatório, portanto, deveria ter incluído esse procedimento com um custo de transação aproximado de US\$ 4.000, o que resultaria, proporcionalmente, no aumento do custo da transação imobiliária.

O economista espanhol Benito Arruñada (2021) critica veementemente a exclusão desse procedimento na análise do "registro de propriedade" norte-americano:

A equipe do Doing Business alegava que a intervenção dos advogados não
era obrigatória, pois os contratantes poderiam optar por se apoiarem
juridicamente a si mesmos (do-it-yourself-conveyancing). Como se sabe,
esse modelo é incompatível em muitos estados, com a contratação de
especialistas que não sejam advogados ou - em todos eles - por determinar
a um só advogado imparcial que represente todas as partes envolvidas).
Diferentemente, em países como Alemanha ou Espanha, para que se registre
uma compra e venda, ou uma hipoteca, é obrigatória a notarização e esse
procedimento sempre foi computado pelo Doing Business.
Consequentemente, a exclusão dos advogados novaiorquinos distorcia
gravemente os resultados, já que os advogados das partes representam um
custo que se situa entre nove e doze vezes mais caro do que os notários em
países europeus com bons registros imobiliários, como a Alemanha e a
Espanha (ao contrário da França ou da Itália, que ainda mantêm registros
documentos).

Dessa forma, não apenas o sistema registral brasileiro é prejudicado em relação ao ranking norte-americano, mas também países como a Alemanha e a Espanha que contam com registros imobiliários fortes (registro de direitos e não de documentos).

Assim, além da ausência do procedimento, há o reflexo na ausência desse custo de transação, que também refletiria diretamente na classificação e no ranking do Doing Business.

\subsection{Inclusão de procedimentos desnecessários}


Por um lado, o relatório omitiu procedimentos norte-americanos, por outro, incluiu procedimentos brasileiros que não são previstos em lei, que não existem ou podem ser obtidos em apenas um ambiente virtual (LEIME, 2021, p. 356). Várias são as certidões relacionadas como procedimentos avulsos e separados pelo relatório Doing Business, como mostra a relação abaixo.

Figura 3 - Certidões relacionadas como procedimentos avulsos pelo Doing Business Brasil 2020

\begin{tabular}{|llc}
\hline & Procedimentos & Prazo \\
\hline $\mathbf{1}$ & Certidões dos cartórios de protestos & 2 dias \\
\hline $\mathbf{2}$ & Certidões de distribuidores cíveis, executivos fiscais e falência & 1 dia \\
\hline $\mathbf{3}$ & Certidão da Justiça do Trabalho & Online \\
\hline $\mathbf{4}$ & Certidão negativa de débitos trabalhistas & Online \\
\hline $\mathbf{5}$ & Certidão de inteiro teor da matrícula & Online \\
\hline $\mathbf{6}$ & Certidão de dados cadastrais do imóvel & Online \\
\hline $\mathbf{7}$ & Certidão de débitos tributários federais e de contribuições previdenciárias & Online \\
\hline $\mathbf{8}$ & Certidão de regularidade de situação do FGTS & Online \\
\hline $\mathbf{9}$ & Certidão da Justiça Federal & Online \\
\hline $\mathbf{1 0}$ & Certidão atualizada da Junta Comercial & Online \\
\hline
\end{tabular}

Fonte: https://www.doingbusiness.org

Essas dez certidões, previstas como dez diferentes procedimentos do sistema registral brasileiro, foram incluídas de forma desnecessária na relação, por algum dos motivos abaixo: I - não previstas em lei; II - dispensáveis em função do Princípio da Concentração ou III passíveis de emissão em conjunto numa única plataforma digital.

As certidões dos cartórios de protesto (1), as certidões de distribuidores cíveis, executivos fiscais e de falência (2), as certidões da Justiça do Trabalho (3), a negativa de 
débitos trabalhistas (4), a certidão de dados cadastrais (6), a certidão da Justiça Federal (9) e a certidão atualizada da Junta Comercial (10) não são exigíveis para qualquer operação imobiliária.

A Central Nacional de Protesto já disponibiliza consulta imediata e gratuita há anos. Em pesquisa realizada com o CPF dos autores, a resultado da consulta foi obtido em 2 segundos pelo sítio eletrônico: cenprotnacional.org.br. Após solicitação pelo sítio eletrônico do Tribunal de Justiça de São Paulo, as certidões são enviadas ao e-mail indicado em 15 segundos.

Apesar de não haver previsão legal para a sua apresentação, caso faça parte do due dilligence do adquirente, podem ser obtidas num único ambiente online por meio de apenas um pedido. Por essa razão, essas consultas deveriam ser consideradas como apenas um procedimento e não 10 distintos. Sua obtenção é imediata e gratuita pelo Guichê de Certidões do Registro de Imóveis do Brasil (www.registrodeimoveis.org.br):

Todas as certidões em um só pedido.

Como contribuição do Registro de Imóveis do Brasil para a melhoria do ambiente de negócios, disponibilizamos gratuitamente uma ferramenta que permite solicitar todas as certidões relevantes para o registro de um imóvel e para o relatório Doing Business, produzido pelo Banco Mundial.

Certidões disponíveis:

\section{Extrajudicial:}

1. Certidão do Registro de Imóveis

2. Protesto - Central Nacional de Protesto

3. Junta Comercial - Certidão da Empresa

Entes Federativos:

4. União - Certidão de Débitos Relativos a Créditos Tributários Federais e à Dívida Ativa da União

5. União - FGTS - Regularidade do Empregador

6. Estado - Certidão de Dívida Ativa

7. Estado - Certidão de Débitos Tributários

8. Município - Certidão Conjunta de Tributos Municipais

9. Município - Certidão de Dados Cadastrais do Imóvel

Judiciário:

10.CNDT - Certidão Nacional de Débitos Trabalhistas

11.TJ - Certidão de Distribuição Cível

12.TJ - Certidão de Distribuição de Falências, Concordatas e recuperações

13.TRF - Certidão de Distribuição 
Ainda, pelo Princípio da Concentração, todos os atos e fatos jurídicos relacionados ao imóvel devem estar publicizados na própria matrícula do imóvel, com apenas duas exceções apontadas no art. 54 da Lei 13.097/2015. O que não constar na matrícula, por força da Lei $\mathrm{n}^{\circ}$ 13.097/2015 não será oponível a terceiro adquirente.

Art. 54. Os negócios jurídicos que tenham por fim constituir, transferir ou
modificar direitos reais sobre imóveis são eficazes em relação a atos
jurídicos precedentes, nas hipóteses em que não tenham sido registradas ou
averbadas na matrícula do imóvel as seguintes informações [...].
[...]
Parágrafo único. Não poderão ser opostas situações jurídicas não constantes
da matrícula no Registro de Imóveis, inclusive para fins de evicção, ao
terceiro de boa-fé que adquirir ou receber em garantia direitos reais sobre o
imóvel, ressalvados o disposto nos arts. 129 e 130 da Lei ${ }^{\circ} 11.101$, de 9 de
fevereiro de 2005 , e as hipóteses de aquisição e extinção da propriedade que
independam de registro de título de imóvel.

A certidão da matrícula do imóvel (5) sim é documento essencial para a lavratura da escritura pública de compra e venda e pode ser solicitada pelas Centrais Eletrônicas do Registro de Imóveis (www.registrodeimoveis.org.br), sendo expedida em até duas horas de acordo com o Provimento 94/2020 do Conselho Nacional da Justiça. Nessa certidão é que devem constar todos os gravames incidentes sobre o imóvel, tais como: hipoteca, alienação fiduciária, penhora, indisponibilidade, acautelatória e outros ônus reais e ações pessoais reipersecutórias (Art. $1^{\circ}$ do Decreto $n^{\circ}$ 93.240/1986).

A certidão de tributos federais e dívida ativa da União (7) já abrange a certidão de regularidade do FGTS (8) desde a Portaria 358/2014 da Secretaria da Receita Federal (www.receita.fazenda.gov.br).

Pela própria metodologia definida pelo Banco Mundial, esses 10 procedimentos deveriam se restringir a apenas um, seja porque as informações relevantes à operação imobiliária estariam presentes na própria certidão de inteiro teor do imóvel (Princípio da Concentração), seja porque poderiam ser obtidas num único ambiente online (Guichê de Certidões). A redução da quantidade de procedimentos impactaria positivamente a classificação e o ranking do sistema registral imobiliário do Brasil no Doing Business.

\section{O FIM DO (UN)DOING BUSINESS}


Recentemente, o Banco Mundial, após praticamente vinte anos de análise do ambiente de negócios de 190 países, anunciou o encerramento definitivo do relatório Doing Business. Após meses de revisão por denúncia de irregularidades, uma empresa de consultoria independente concluiu que houve alteração indevida de dados, a fim de favorecer o ranking de alguns países. O resultado da consultoria levou em consideração análise de cinco milhões de arquivos, revisão de oitenta mil documentos e entrevista de dezenas de empregados e exempregados (HALE, 2021).

Benito Arruñada, crítico há anos do plano metodológico e organizativo do estudo globa realizado pelo Banco Mundial, argumenta que "desde o seu lançamento, para evitar a oposição dos Estados Unidos (principal financiador do Banco), os responsáveis pelo projeto, escolheram uma metodologia parcial" (2021). De acordo com o economista espanhol, a metodologia não valorizava o benefício efetivo decorrente das regulamentações, mas apenas alguns de seus custos explícitos. Assim, a partir do momento que se analisa sistemas registrais de direitos (segurança forte) em comparação com registros de documentos (segurança fraca), os resultados apresentarão disparidades significativas.

Por mais que a metodologia do Doing Business não levasse em consideração apenas requisitos previstos em lei, mas também a prática do mercado, pela análise comparativa do "registro de propriedade" brasileiro com o norte-americano, ficavam evidentes as fragilidades do relatório.

No entanto, não podemos deixar de considerar que também houve um legado positivo do Doing Business para o Brasil. Mesmo com a discordância em relação ao método utilizado, o esforço dos registradores de imóveis para melhorar sua posição foi constante. E assim, a fim de atender às expectativas da metodologia do relatório do Banco Mundial, várias inovações no sistema registral foram realizadas.

Nos últimos anos, os registradores de imóveis, por meio do Registro de Imóveis do Brasil, entidade nacional que congrega vinte e cinco das vinte e sete unidades federativas, desenvolveram várias ferramentas para aumentar, ainda mais, o espectro de informações relacionadas às operações imobiliárias. Houve, portanto a criação do Guichê de Certidões, do Mecanismo de Reclamações, do Mapa Nacional de Transações Imobiliárias, do Portal 
Estatístico Registral, ferramentas que contribuíram consideravelmente para a publicidade registral. (www.registrodeimoveis.org.br)

Figura 4 - Serviços eletrônicos do Registro de Imóveis

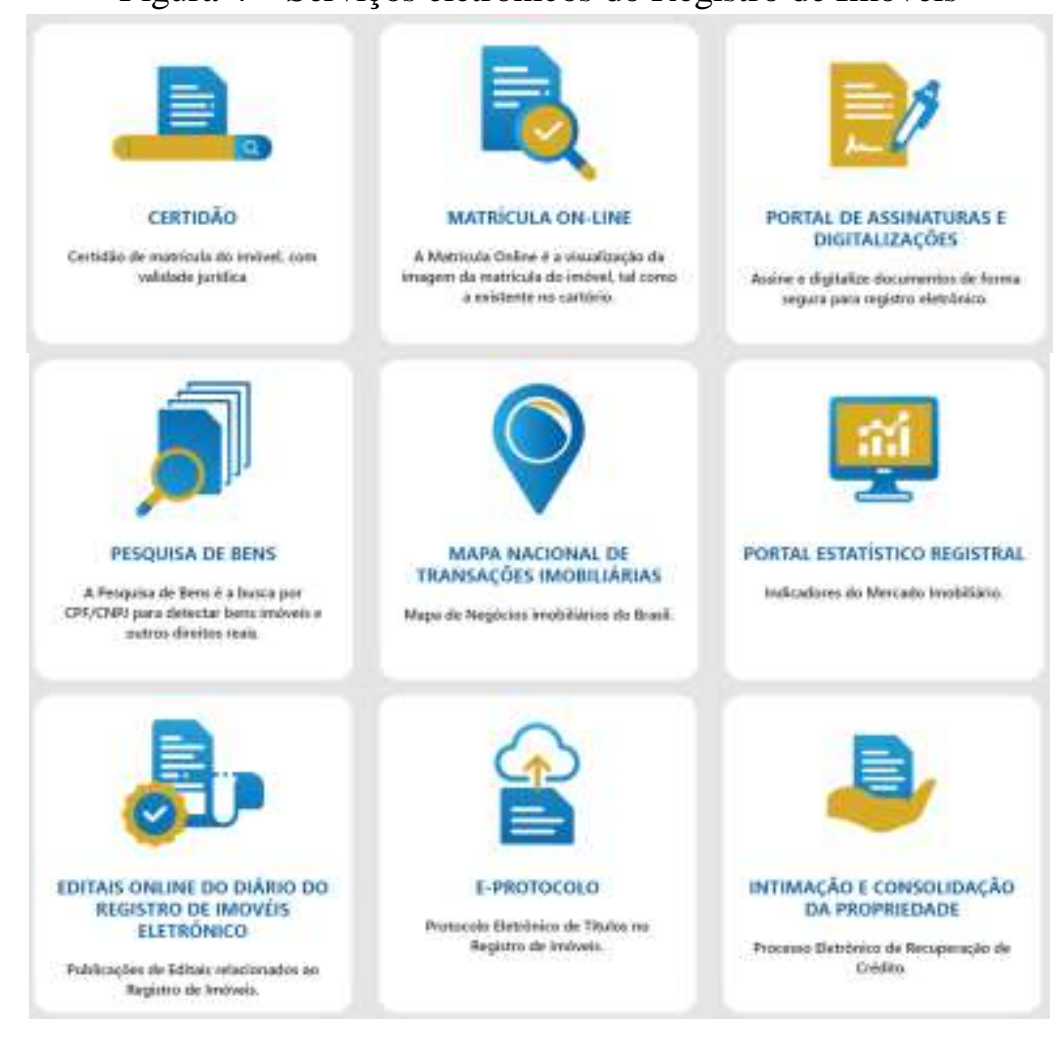

Fonte: www.registrodeimoveis.org.br

As inovações abrangem hoje uma gama variada de serviços prestados eletronicamente à sociedade e ao Poder Público. O portal disponibiliza serviços eletrônicos de emissão de certidão assinada eletronicamente, visualização das matrículas online, ambiente de assinatura eletrônica, pesquisa de bens com base no CPF ou no CNPJ, publicação de editais online, protocolo eletrônico de títulos particulares ou públicos e ferramenta de intimação e consolidação da propriedade de alienação fiduciária de bem imóvel.

Por mais que exista um portal único de acesso aos serviços eletrônicos, esses são hoje administrados, de forma diferente, por cada entidade estadual. Dessa forma, o usuário, por meio do portal, ingressa em cada central estadual com logins, senhas e formas de pagamento 
diversas. Exemplificando, o interessado por meio do acesso ao portal nacional, clica no estado de Santa Catarina e acessa a Central do Registro de Imóveis de Santa Catarina ${ }^{6}$.

O ideal é que as 3.600 unidades de Registro de Imóveis possam ser acessadas por um portal único, com os mesmos serviços, mesmo login, senha e forma de pagamento. E esse projeto nacional está virando realidade com o lançamento do SAEC - Serviço de Atendimento Eletrônico Compartilhado, lançado em 21/09/2021 pelo Conselho Nacional da Justiça (www.registradores.onr.org.br).

O Serviço de Atendimento Eletrônico Compartilhado é uma plataforma integradora de hardwares e softwares de suporte ao Sistema de Registro Eletrônico de Imóveis (SREI), na forma prevista nos arts. 24 e seguintes do Provimento $n^{\circ}$ 89/2019/CNJ. Trata-se de compromisso assumido voluntaria e colaborativamente pelo Operador Nacional do Sistema de Registro Eletrônico de Imóveis - ONR, associação sem fins lucrativos, voltado à prestação de serviços de interoperabilidade entre as informações constantes nas serventias extrajudiciais e os usuários, permitindo o acesso remoto e eletrônico ao registro imobiliário e, inclusive, o desenvolvimento de soluções ao Poder Público, como a Central Nacional de Indisponibilidade de Bens e o Ofício Eletrônico. Por meio desse ambiente, o usuário acessa remotamente as serventias extrajudiciais de todo o país.

\section{CONCLUSÃO}

O projeto Doing Business tem sido desenvolvido pelo Banco Mundial há quase duas décadas e tinha como objetivo principal ajudar os países, de modo global, a melhorarem seus ambientes de negócio. Uma das análises realizadas era referente à qualidade, ao prazo, à complexidade e ao custo do registro das transações imobiliárias. Há anos que o Brasil recebe

6 Central do Registro de Imóveis de Santa Catarina. Disponível em: <https://central.centralrisc.com.br/auth/login>. Acesso em: 30 set. 2021. 
uma avaliação muito baixa nessa área, o que serve como um dos fatores para alguém não querer arriscar empreender no país.

Pelo potencial prejuízo que uma classificação equivocada pode ocasionar aos países é que a metodologia utilizada deve ser transparente, objetiva e correta. Esses necessários requisitos não foram identificados pela análise do relatório de "registro de propriedade" do Brasil e dos Estados Unidos. Fragilidades de metodologia geraram ruptura na credibilidade do relatório Doing Business, a ponto de ter havido manifestação recente de seu fim. Nesse ponto, a análise foi que o relatório estava corrompido metodológica e eticamente, a fim de favorecer determinadas economias. A partir do momento que temos distorções propositais ou não o relatório passa a indiretamente prejudicar os países classificados erroneamente, provocando um undoing business.

Entre Brasil e Estados Unidos, observaram-se inconsistências na análise e na classificação da qualidade, do prazo, da complexidade e do custo. Uma delas era a ampla margem de subjetividade na coleta e na análise de informações, o que denominamos de metodologia "porta aberta". Exemplo disso era o relatório apontar quatorze diferentes procedimentos registrais imobiliários no Brasil, contra apenas quatro nos Estados Unidos, quando se sabe que a fase do due diligence norte-americano é infindável, na medida em que o sistema de registro (de documentos e não de direitos) não conta com a concentração dos gravames na certidão do imóvel, como ocorre no Brasil.

Outro ponto a ser objeto de reflexão e de ajuste é a cultura do "dois pesos e duas medidas". Tanto para a redação do contrato (deed) quanto para o registro do título perante o Registro de Imóveis norte-americano, o relatório computava, para cada um dos procedimentos, somente um dia, com a justificativa de que os efeitos do registro retroagem à data do protocolo. No Brasil, temos essa regra de retroação dos efeitos prevista no art. 1.246 do Código Civil e, não obstante, o prazo computado foi de 15 dias.

E um terceiro aspecto que gerava uma inconsistência significativa na classificação global era a omissão do procedimento de contratação de advogado para a operação imobiliária, o que, na metade dos estados federados, é, inclusive, obrigatório e não apenas recomendável. 
Ao mesmo tempo que nos despedimos do Undoing Business, esperamos pelas necessárias correções de metodologia para que possamos voltar a ter um Doing Business saudável e positivo economicamente para todos os países envolvidos.

\section{REFERÊNCIAS}

WORLD BANK. Disponível em: https://www.worldbank.org/en/about. Acesso em: 31 ago. 2021.

WORLD BANK. Open Knowledge Repository. Disponível em: $<$ https://openknowledge.worldbank.org $>$. Acesso em: 06 set. 2021.

WORLD, BANK. Registering Property methodology. Disponível em: $<$ https://www.doingbusiness.org/en/methodology/registering-property $>$ Acesso em: 06 set. 2021.

BANCO CENTRAL DO BRASIL. Disponível em: https://www.bcb.gov.br/. Acesso em: 30 ago. 2021.

DOING BUSINESS. Disponível em: https://www.doingbusiness.org/en/methodology/registering-property. Acesso em: 20 set. 2021.

LEE, Nick, LINGS, Ian. Doing Business Research - A Guide to Theory and Practice.London: Sage Publications, 2008, p. 70.

ARRUÑADA, Benito. En la muerte de Doing Business. Voz Populi, set. 2021. Disponível em: <https://www.vozpopuli.com/opinion/muerte-doing-business.html $>$. Acesso em: 21 set. 2021.

LEIME, Mayra Zago de Gouveia Maia. O Tempo para a efetivação de uma aquisição imobiliária nos Estados Unidos e no Brasil: um comparativo entre Nova York e São Paulo com base na metodologia do relatório Doing Business. In BRANDELLI, Leonardo. Transmissão da Propriedade Imóvel: Uma Análise Comparada Brasil - Estados Unidos. Salvador: Editora JusPodivm, 2021, p. 356-364.

BRANDELLI, Leonardo. Transmissão da Propriedade Imóvel: Uma Análise Comparada 
Brasil - Estados Unidos. Salvador: Editora JusPodivm, 2021, p. 356-364.

REGISTRO DE IMÓVEIS DO BRASIL. Disponível em: https://www.registrodeimoveis.org.br/. Acesso em: 20 set. 2021.

BRASIL. Decreto $\quad \mathrm{n}^{\circ} \quad 93.240 / 1986 . \quad$ Disponível em: http://www.planalto.gov.br/ccivil_03/decreto/Antigos/D93240.htm. Acesso em: 20 set. 2021.

RECEITA FEDERAL. Disponível em: http://normas.receita.fazenda.gov.br/sijut2consulta/. Acesso em: 20 set. 2021.

HALE, Wilmer. Investigation of Data Irregularities in Doing Business 2018 and Doing Business 2020 - Investigation Findings and Report to the Board of Executive Directors. Disponível em: <

https://thedocs.worldbank.org/en/doc/84a922cc9273b7b120d49ad3b9e9d3f90090012021/original/DB-Investigation-Findings-and-Report-to-the-Board-of-ExecutiveDirectors-September-15-2021.pdf $>$. Acesso em: 21 set. 2021. 